\title{
A Prevalence Study of Multiple Sclerosis in the Crowsnest Pass Region of Southern Alberta
}

\author{
G.M. Klein, M.S. Rose and T.P. Seland
}

\begin{abstract}
Reports of a high prevalence rate for multiple sclerosis in Southern Alberta led to an epidemiologic study of this disease in the Crowsnest Pass and Cardston regions. In Cardston, the prevalence rate for multiple sclerosis was 88 per 100,000. In the Crowsnest Pass, the prevalence rate was 217 per 100,000. Previous epidemiologic studies of the prevalence rate of multiple sclerosis in Western Canada have shown rates between 93 and 111 per 100,000. Two prevalence studies of multiple sclerosis in Barrhead County, Alberta and Westlock County, Alberta show prevalence rates of 196 and 201 per 100,000. The prevalence rate in the Crowsnest Pass is comparable to the prevalence in Barrhead County and Westlock County, Alberta. However, there is no statistically significant difference between prevalence rates in the Cardston and Crowsnest Pass regions and our overall feeling is that the results of studies of small populations should be interpreted with caution.
\end{abstract}

Résumé: Étude de prévalence de la sclérose en plaques dans la région de Crowsnest Pass dans le sud de l'Alberta. Une étude épidémiologique de la sclérose en plaques (SEP) dans le sud de l'Alberta a été entreprise à la suite de rapports faisant état d'une prévalence élevée de cette maladie dans la région de Crowsnest Pass et de Cardston. Dans Cardston, le taux de prévalence de la SEP était de 88 par 100,000 habitants. Dans Crowsnest Pass, le taux de prévalence était de 217 par 100,000 habitants. Des études épidémiologiques antérieures ont montré des taux de prévalence de la SEP entre 93 et 111 par 100,000 habitants dans l'ouest du Canada. Deux études de prévalence de la SEP dans les comtés de Barrhead et de Westlock en Alberta montrent des taux de prévalence de 196 et 201 par 100,000 habitants respectivement. Le taux de prévalence dans la région de Crowsnest Pass est comparable à celui des comtés de Barrhead et de Westlock en Alberta. Cependant, la différence entre les taux de prévalence dans la région de. Cardston et la région de Crowsnest Pass n'est pas significative et nous sommes d'avis que les résultats d'études faites sur de petites populations doivent être interprétées avec prudence.

Can. J. Neurol. Sci. 1994; 21: 262-265

In 1980, Kurtzke' ${ }^{1}$ evaluated almost 200 different epidemiologic studies of MS, and since then many more have been published. These studies have demonstrated that MS has a clear geographic distribution with high, medium and low risk areas for the disease.

There have been a large number of epidemiologic studies in Canada. Prevalence rates in Halifax, Kingston, London and Newfoundland and Labrador range from 25 to 94 per $100,000 .^{2-5}$ In Winnipeg, Manitoba, the prevalence rate was estimated at 35 per $100,000 .^{6}$ Studies from British Columbia ${ }^{7}$ and Saskatoon, Saskatchewan ${ }^{8}$ showed prevalence rates of 93/100,000, and $111 / 100,000$. Clearly, older studies of the prevalence of MS are harder to evaluate, as case ascertainment must be considered more problematic in the absence of modem diagnostic tests.

Initial rumours of a high prevalence rate of $\mathrm{MS}$ in the Crowsnest Pass and Cardston regions of Southern Alberta led to an epidemiological study of this disease in those areas. Following our preliminary report ${ }^{9}$ of a high prevalence rate of MS in the Crowsnest Pass area of Alberta, two further reports were published by Warren and Warren ${ }^{10,11}$ reporting high prevalence rates in Barrhead County and Westlock County, Alberta.

\section{Materials ANd Methods}

The Crowsnest Pass and Cardston regions both lie close together in Southern Alberta. The Crowsnest Pass region comprises several small towns, as well as a rural area. The total population of the region is 6,912 of whom 3,304 live within small towns and the remainder are classified as rural dwellers.

The Cardston region comprises a small town with a population

From the Departments of Clinical Neurosciences and Community Health Sciences, University of Calgary and Calgary General Hospital, Calgary. RECEIVED MAY 6, 1993. ACCEPTED IN FINAL, FORM MARCH 9, 1994.

Reprint requests to: Dr. G.M. Klein, Department of Clinical Neurosciences, Calgary General Hospital, M4-022, 841 Centre Avenue E, Calgary, Alberta, Canada T2E 0AI 
of 3,497 , and a rural area with a population of 4,419 , giving a total population of $7,916 .^{12}$

The records of the Multiple Sclerosis Clinic in Calgary were screened, and all MS patients living within the relevant areas were identified. All family doctors within the relevant geographic areas were contacted directly by the investigators or by a research nurse. They were asked to contact all MS patients in their practices and inform them of the prevalence study. The patients were invited to contact the research nurse. No patients refused to participate and all did contact the research nurse. The purpose of the study was explained to each patient in detail and written informed consent for their participation in the study was obtained. A neurological examination and a review of all the records were undertaken in each case. Cases of definite and probable multiple sclerosis were identified. As part of the history taking, patients were asked about current and past members of their communities who might have MS. Patients were classified as clinically definite, laboratory supported clinically definite, clinically probable, and laboratory supported clinically probable as defined by the modified Schumacher criteria. ${ }^{13}$ No patients with clinically possible MS were identified, and none are therefore included in this study. In addition, patients were classified as to the nature of their disease, relapsing/remitting, relapsing/progressing, or chronic/progressing disease.

Information collected on each patient included age, gender, place of birth, place of habitation throughout their life, ethnic origin, exposure to environmental factors, family history, the date of their first symptom, and the nature of symptoms.

The prevalence date was set at June 21, 1989. One patient was not in the Crowsnest Pass on that date, and was contacted later that year. A final patient who had been missed in the original survey was located early in 1990 . She had been living in the Crowsnest Pass on the relevant date, but had been inadvertently missed by the initial investigation.

\section{Results}

In Cardston, ten patients were referred to us. Of these, seven had definite or probable MS. This gave a prevalence rate of 88 per 100,000 (95\% Confidence Interval $(\mathrm{CI})$ from 36-182 when the Poisson distribution is applied).

In the Crowsnest Pass, twenty patients were referred altogether. Of these, fifteen had definite or probable MS. This gives a prevalence rate of 217 per $100,000(95 \% \mathrm{CI}=121.5-358)$.

Of 15 patients with definite or probable MS, ten were female and five were male. Eleven had clinically definite MS, one had laboratory-supported clinically definite MS, and the remaining three patients had clinically probable disease. Six patients had relapsing/remitting disease, four had relapsing/progressing disease, and five had chronic progressing disease. The year of first onset of symptoms ranged from 1953 up until 1988.

\section{Discussion}

In Cardston, the prevalence rate of MS is 88 cases per 100,000 . This falls very close to the prevalence rate previously described in British Columbia and Saskatoon. Of seven identified cases of MS, only two had spent all or most of the first fifteen years of their life in Cardston. The other five cases had migrated into the Cardston area after the age of 15 .
In the Crowsnest Pass, there were 15 cases of MS. The majority, nine out of fifteen cases, had spent all or most of their first fifteen years in the Crowsnest Pass region.

The overall prevalence rate of MS in the Crowsnest Pass appears to be higher than expected for Western Canada, and actually comparable to the prevalence rates of MS in Barrhead County and Westlock County, Alberta described by Warren and Warren.

There are several possible explanations for this.

MS is probably a multifactorial disease where both genetic and environmental factors play a role. ${ }^{14}$ If the Crowsnest Pass area contains a few families who are genetically predisposed to MS, then this factor alone might be biasing the prevalence data. This possibility can only be proven or disproven by further genetic studies of the MS population of the Crowsnest Pass. All MS patients in the Crowsnest Pass are of caucasian descent.

None of the MS patients from the Crowsnest Pass reported a close family member with MS. One patient with clinically definite MS had a daughter who was referred to us as well with a history of possible MS, but this diagnosis was not confirmed on further evaluation. This differs quite strikingly from the reports of Warren and Warren, who reported that 35\% of Barrhead MS patients had a close family member with MS.

In the past ten years, the Crowsnest Pass has been economically depressed. Migration of healthy, young people out of the area, leaving behind the elderly and infirm, could create a false impression of a very high prevalence rate. This phenomenon has been described before in a North American study, and has been referred to as condensation. ${ }^{15}$ There is some logic to this argument. Between 1981 and 1986, the population of the Crowsnest Pass fell by 5.3\%. Over the same time course, the population of Calgary, Alberta increased by $7.3 \%$, showing that the population of the Crowsnest Pass area was indeed falling at the same time as the population of close larger urban centres was rising. Arguing against this, Warren and Warren suggested that the disabled are likely to move to large urban areas because of the greater variety of services available there, which might mean that the prevalence rates in both Barrhead County and the Crowsnest Pass are actually underestimated. Interestingly, the patients in the Crowsnest Pass with MS between them provided a list of eight individuals that they believed to have MS, who had migrated out of the Crowsnest Pass Region.

It is possible that the high prevalence rate of MS in the Crowsnest Pass actually represents a true epidemic of MS. Previous epidemics of MS have been reported, ${ }^{16,17}$ and these occurred in isolated communities, that were exposed to a new environmental factor.

As part of this prevalence study, the year of onset of symptoms was documented. MS has appeared on a consistent basis in the Crowsnest population, and this does not have the characteristics of a point source epidemic.

A limitation of these studies from Alberta is that the populations studied are simply too small to estimate the prevalence rates precisely, resulting in wide confidence intervals. The confidence interval indicates the range of estimated values of the prevalence rate that are most compatible with the data in the sample. A comparison of the $95 \%$ confidence intervals (Figure 1) for the prevalence rate for MS in the Cardston, Crowsnest 


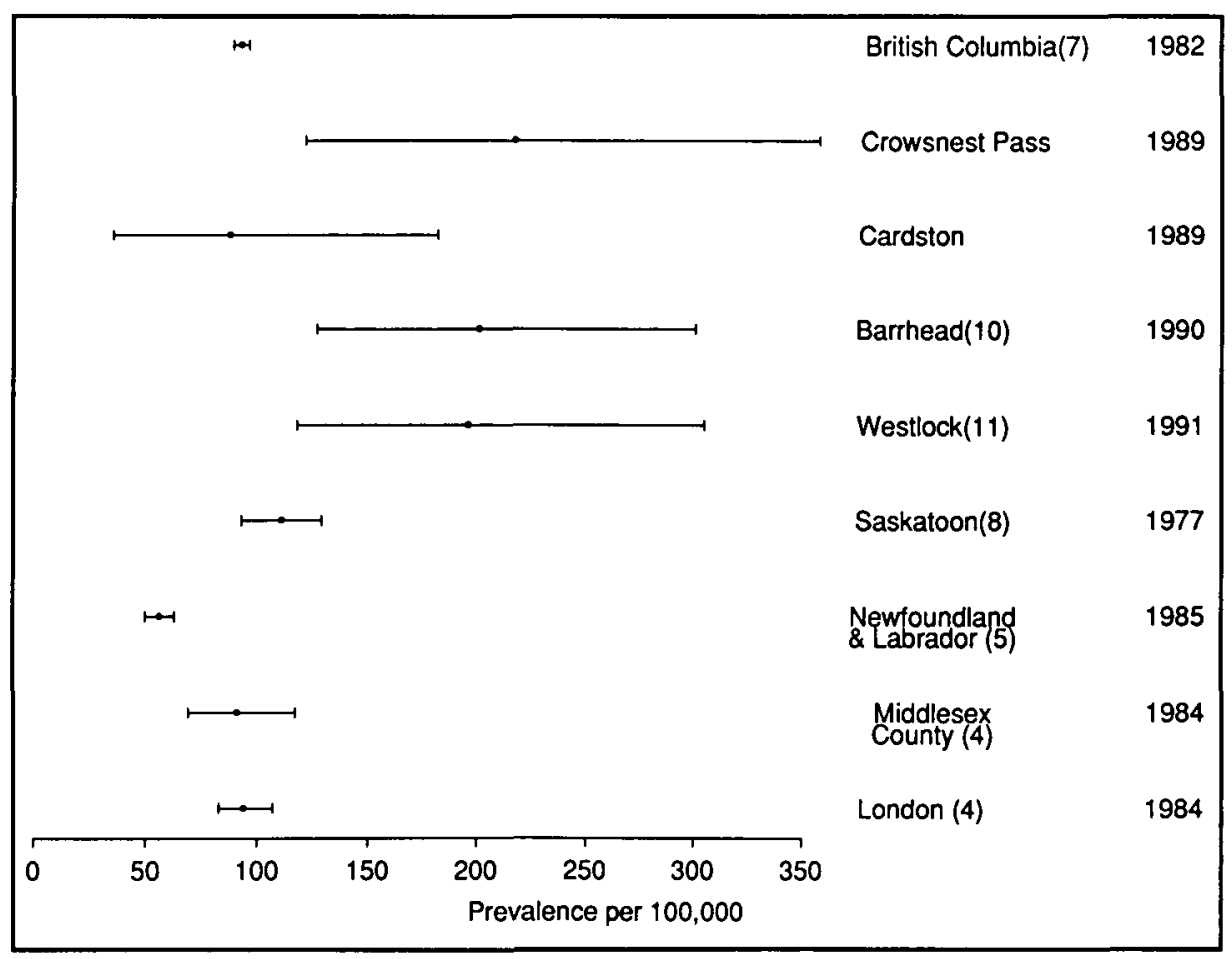

Figure 1: Estinated prevalence rates with 95\% confidence intervals for the Crowsnest Pass and Cardston areas compared with previous studies.

Pass, Barrhead and Westlock County areas suggests that none of the prevalence rates for these four areas of Alberta are statistically significantly different, since there is a large range of values of the estimates that are compatible with the data in all four samples.

Other estimates of prevalence rates in Western Canada were made on much larger populations, resulting in greater precision of the estimates. A confidence interval was not given for the prevalence rate in B.C. However, from the reported 2596 cases and a population of $2,791,398$ and using the normal approximation to the Poisson distribution, the $95 \%$ confidence interval of the prevalence rate in B.C. is $89.42-96.58$ per 100,000 . Comparison of the $95 \%$ confidence intervals suggests: 1) No significant difference between the prevalence rate estimated for the Cardston area and those for Saskatoon and B.C. 2) The estimated prevalence rates are significantly higher for the Crowsnest Pass, Barrhead and Westlock areas compared to the B.C. prevalence rate. 3) The estimated prevalence rate for Saskatoon is lower than the prevalence rates in the Crowsnest Pass, Barrhead and Westlock areas, however there is a small overlap of the $95 \%$ confidence intervals. The wide confidence intervals for the Alberta data make comparison with other prevalence rates, particularly Saskatoon, very difficult. Thus caution should be exercised in the interpretation of the results for these studies of small populations. 4) Direct comparison of prevalence rates between newer and older studies is made even more difficult by differences in diagnostic tests that make case ascertainment much easier in more recent studies.

Overall, we strongly feel that caution must be exercised in the interpretation of the results of studies based on small populations.

\section{Conclusion}

An epidemiologic study of the prevalence rate of MS in the Crowsnest Pass and Cardston regions revealed prevalence rates of 217 and 88 per 100,000 respectively. Confidence intervals for both regions overlap and also overlap with other reported prevalence rates. Although there are many possible explanations for the high prevalence rate reported for the Crowsnest Pass, the true explanation may be simple studies of small populations have limited statistical precision. It may indeed be true that further studies of the prevalence of MS are unlikely to change our views of MS in any fundamental way. ${ }^{14}$

\section{REFERENCES}

1. Kurtzke JF. Epidemiologic contributions to multiple sclerosis: an overview. Neurology 1980; 30: 61-79.

2. Alter M, Allison RS, Talbert OR, et al. Geographic distribution of multiple sclerosis. World Neurol 1960; 1: 55-70.

3. White DN, Wheelan L. Disseminated sclerosis: a survey of patients in the Kingston, Ontario area. Neurology 1959; 9: 256272.

4. Hader WJ, Elliot M, Ebers GC. Epidemiology of multiple sclerosis in London and Middlesex County, Ontario, Canada. Neurology 1988; 38: 617-620

5. Pryse-Phillips WEM. The incidence and prevalence of multiple sclerosis in Newfoundland and Labrador, 1960-1984. Ann Neurol 1986; 20: 323-328.

6. Stazio A, Kurland L, Bell L, et al. Multiple sclerosis in Winnipeg, Manitoba: methodological considerations of epidemiologic survey. Ten year follow-up of a community wide study and population re-survey. J Chronic Dis 1964; 17: 415-438.

7. Sweeney VP, Sadovnick AD, Brandejs V. Prevalence of multiple sclerosis in British Columbia. Can J Neurol Sci 1986; 13: 47-51.

8. Hader WJ. Prevalence of multiple sclerosis in Saskatoon. Can Med Assoc J 1982; 127: 295-297.

9. Klein GM, Seland TP, Barclay L, et al. An epidemiologic study of multiple sclerosis in the Crowsnest Pass and Cardston regions of Southern Alberta (Abs). Can J Neurol Sci 1990; 17: 241. 
10. Warren $S$ and Warren KG. Prevalence of multiple sclerosis in Barrhead County, Alberta, Canada. Can J Neurol Sci 1992; 19: $72-75$.

11. Warren SA and Warren KG. Prevalence of multiple sclerosis (MS) in Westlock County: another excess risk area confirmed in Alberta. Can J Neurol Sci 1992; 19: 295.

12. 1986 Census of Canada. 1981 Census of Canada. Statistics Canada.

13. Poser CM, Paty DW, Scheinberg L, et al. New diagnostic criteria for multiple sclerosis: guidelines for research protocols. Ann Neurol 1983; 13: 227-231.
14. Martyn C. The epidemiology of multiple sclerosis. In: Matthews, WB, ed. McAlpine's Muliple Sclerosis, 2nd Ed. Edinburgh, London, Melbourne and New York, 1991: 3-40.

15. Conomy JP, Namey M, Rudick R, et al. MS in Galion: a cluster in time, or a cluster in space? CMSC, Los Angeles, California. May, 1989.

16. Kurtzke JF, Hyllested K. Multiple Sclerosis in the Faroe Islands: clinical and epidemiological features. Ann Neurol 1979; 5: 6-21.

17. Kurtzke JF, Gudmundsson KR, Bergmann S. Multiple sclerosis in Iceland: a postwar epidemic. Neurology 1980; 30: 437. 